BMJ Open

Diabetes

Research

\& Care

\section{Cost-effectiveness of a self-management and comprehensive training intervention in patients with type 2 diabetes up to 5 years of diagnosis in a specialized hospital in Mexico City}

To cite: Hernández-Jiménez $\mathrm{S}$, García-Ulloa AC, Anaya P, et al. Cost-effectiveness of a self-management and comprehensive training intervention in patients with type 2 diabetes up to 5 years of diagnosis in a specialized hospital in Mexico City. BMJ Open Diab Res Care 2021;9:e002097. doi:10.1136/ bmjdrc-2020-002097

- Supplemental material is published online only. To view, please visit the journal online (http://dx.doi.org/10.1136/ bmjdrc-2020-002097).

Received 29 December 2020 Accepted 5 June 2021

Check for updates

C Author(s) (or their employer(s)) 2021. Re-use permitted under CC BY-NC. No commercial re-use. See rights and permissions. Published by BMJ.

For numbered affiliations see end of article.

Correspondence to Dr Ana Cristina García-Ulloa; dra_ulloa@yahoo.com.mx

\section{ABSTRACT}

Introduction To assess the cost-effectiveness of a multidisciplinary and comprehensive innovative diabetes care program (CAIPaDi) versus usual treatment in public health institutions.

Research design and methods Using a costeffectiveness analysis, we compared the CAIPaDi program versus usual treatment given in Mexican public health institutions. The analysis was based on the IQVIA Core Diabetes Model, a validated simulation model used to estimate long-term clinical outcomes. Data were prospectively obtained from the CAIPaDi program and from public databases and published papers. Health outcomes were expressed in terms of life-years gained and qualityadjusted life years (QALYs). Health and economic outcomes were estimated from a public perspective and discounted at $5 \%$ per year over a 20 -year horizon. Costs are reported in US dollars (US\$) of 2019. A probabilistic sensitivity analysis was performed using life-years gained and QALYS. Results The CAIPaDi costs on average US\$559 $(95 \% \mathrm{Cl}$ : $-\$ 879$ to $-\$ 239)$ less than the usual treatment $(95 \% \mathrm{Cl}$ : $-\$ 879$ to $-\$ 239$ ) and produced a difference in mean life-years gained $(0.48,95 \% \mathrm{Cl}: 0.45$ to 0.52$)$ and mean QALYs (1.43, 95\% Cl: 1.40 to 1.46). The cost-effectiveness ratio resulted in a saving per life-year gained of -US\$1155 (95\% Cl: $-\$ 1962$ to -\$460). Mean differences in QALYS resulted in a saving per QALY of -US\$735 $(95 \% \mathrm{Cl}$ : $-\$ 1193$ to $-\$ 305)$. Probabilistic sensitivity analysis proved the results are robust on both life-years gained and QALYS. Conclusions CAIPaDi has a better cost-effectiveness ratio than the usual therapy in Mexican public health institutions.

\section{INTRODUCTION}

Type 2 diabetes mellitus (T2DM) is a leading cause of disability and death in Mexico. ${ }^{1}$ Among people living with T2DM in Mexico, nearly 20000 amputations occur every year. ${ }^{1}$ Additionally, more than 80000 persons

\section{Significance of this study}

What is already known about this subject?

- Diabetes requires high costs of care, which are greatly increased by disabling complications.

What are the new findings?

- The CAIPaDi program is a comprehensive and multidisciplinary care model focused on the early stages of type 2 diabetes mellitus (T2DM) and based on patient training for the prevention of complications. This analysis proves that the model is cost-effective, in life-years gained and quality-adjusted life years (QALYS), compared with the usual therapy.

How might these results change the focus of research or clinical practice?

- The implementation of a comprehensive, multidisciplinary and preventive model can mitigate the economic impact of diabetes, prolong lifespan and improve quality of life.

with T2DM progressed to renal failure and depend on replacement therapies to stay alive. $^{2}$ Mortality is high in patients between 35 and 74 years with diabetes, with risk ratios of 2.1 (95\% CI 1.9 to 2.2) in patients undiagnosed and 3.0 (2.8 to 3.3) for patients with a previous diagnosis and HbAlc $<9 \%$ and 5.2 (4.9 to 5.5 ) in those with $\mathrm{HbAlc} \geq 9 \%{ }^{3}$ In 2016, 105574 persons died prematurely due to all types of diabetes, with an average age of 66.7 years old. ${ }^{4}$ The impact of the T2DM is reflected not only in the high demand for healthcare services and medicines, but also in the patients' productivity level, which directly affects the family income. In a comprehensive 
research exercise, the direct costs related to the healthcare resources utilization of T2DM in Mexico were estimated in 2013 as $1.1 \%$ of the gross domestic product (GDP) (about US\$14056 billion). Additionally, the indirect costs, those related to premature mortality and disability or handicap to contribute to the labor market, were estimated in $1.1 \%$ extra of the GDP (about US $\$ 14359$ billion). ${ }^{56}$ (Exchange rate: average daily reported by Bank of Mexico for 2013 https://www.banxico.org.mx/ tipcamb $/$ main.do?page $=$ tip\&idioma $=$ sp

It has been shown that, in all chronic diseases with multifactorial etiology, with various therapeutic alternatives and with great heterogeneity of complications, better results can be obtained in the patient when a multidisciplinary care team is formed. ${ }^{7-9}$ For such teams to be effective, it is recommended to follow certain principles. Among them is the transmission of knowledge to the patient and developing skills for self-care. The team must include actions of education, cooperative and coordinated assistance based on guidelines or standardized procedures, with operational definitions and detailed descriptions of the interventions to be followed. All interventions used by the multidisciplinary team should seek to be simple, practical and easy to apply. The team members must be clear about their specific functions, which will be complementary. Tools should be implemented for auditing the actions that are carried out in order to reinforce those that give good results and correct areas of opportunity. A multidisciplinary diabetes team should include health professionals who are dedicated to the approach and resolution of medical or physical aspects, those dedicated to the emotional state, who promote favorable changes in lifestyle (diet and physical activity/exercise) and those dedicated to education about the disease. This approach to treating diabetes has been shown to increase the proportion of people who are better educated regarding their disease, achieving and maintaining goals for metabolic and blood pressure control, greater changes in their lifestyles, and improved well-being, mental health and quality of life in general. This produces a significant reduction in the personal and economic burden of the patient, his family and society in general. ${ }^{1011}$

According to the National Survey on Nutrition and Health 2018, 10.3\% of adults older than age 20 years had a medical diagnosis of T2DM. Although $87.7 \%$ reported to receive at least one glucose-lowering agent, only $15.6 \%$ had at least one glycated hemoglobin (HbAlc) measurement, $20.9 \%$ had a foot examination and $4.7 \%$ had a microalbuminuria test during the year before. ${ }^{12}$ However, quality of care is highly heterogeneous nationwide. This serious public health problem in general has been attended for years through a classic medical model in which fundamentally patients attend medical visits to receive drug prescriptions, with little information about their disease and with low commitment to self-care behaviors. There have been some efforts from different Mexican institutions to improve and innovate the healthcare model for diabetes, but until recently, they have published only one cost-effectiveness evaluation which found that a multidisciplinary healthcare model for patients with T2DM is cost-effective versus a 'conventional healthcare model'. ${ }^{13}$ Also, there is similar experience in Argentina. Here, González et al ${ }^{14}$ assessed the cost-effectiveness of education of people with T2DM over a year versus education and support delivered by trained peers with T2DM. They found that education through peers as a complement to control and provide treatment for the disease is cost-effective compared with traditional education. However, evidence is still scarce about the long-term outcomes in economic evaluations of public health interventions targeted to patients with T2DM relative to usual treatments in Mexico or in Latin American countries.

The Center of Comprehensive Care for the Patient with Diabetes (CAIPaDi-an acronym for its name in Spanish) is an innovative intervention designed to provide education to patients implemented by the National Institute of Medical Science and Nutrition Salvador Zubirán in Mexico City. ${ }^{115}$ This report describes a cost-effectiveness analysis of the CAIPaDi program versus usual treatment in public health institutions. These results constitute a robust evaluation of a healthcare intervention tackling a complex disease, and shed some light on how costeffectiveness evaluation of innovative interventions may improve the decision-making process in Mexico.

\section{RESEARCH DESIGN AND METHODS}

This study was an economic evaluation (cost-effectiveness analysis), comparing the long-term (20 years) health outcomes: life years (LYs) and quality-adjusted life years (QALYs) and the direct medical costs associated with the CAIPaDi program versus the conventional model of healthcare in Mexican public institutions for patients with T2DM using the robust, previously validated 'IQVIA Core Diabetes Model (IQVIA CDM)'. The structure, data inputs and validation of the IQVIA CDM have been published elsewhere. ${ }^{16} 17$ Additionally, online supplemental appendix 1 includes information regarding the IQVIA CDM.

\section{The CAlPaDi program}

The study design for the CAIPaDi program has been described in detail elsewhere. ${ }^{11}$ In summary, the CAIPaDi program is an intervention designed to provide education and empowerment techniques using simple low-cost interactive tools over a short period of time followed by at-distance support using internet or cell phone technology. The target population consists of patients with T2DM, aged 18-70 years, non-smokers, less than 5 years of diagnosis, and without disabling complications.

The intervention consists of a training of four initial 6-hour monthly visits followed by annual evaluations in the center with a continuous at-distance support system. The interventions are delivered in individualized or 




Figure 1 Scatter plot of incremental cost against incremental life-years and quality-adjusted life years (QALYs) for CAIPaDi versus usual treatment years. (A) Costeffectiveness scatter plot of the life-years gained versus the incremental costs. (B) Cost-effectiveness scatter plot of the QALYs gained versus the incremental costs. Each point represents a sensitivity analysis run.

group sessions provided by nine specialized health professionals: endocrinology, ophthalmology/optometry, physical activity, nutrition, dentist, diabetes education, psychology, psychiatry and foot care. ${ }^{11} 15$ Each session is $30 \mathrm{~min}$ long with the healthcare professionals. Group sessions are $45 \mathrm{~min}$ long. Every visit included the nine healthcare professional interventions in a face-toface session held at the CAIPaDi center. Patients participated in individual or group sessions. Each intervention followed a procedure manual to standardize the sessions with all the patients. In the first visit, a complete assessment of the patient provides information required to adapt the treatment in an individualized form. The second visit, a problem-oriented evaluation, is performed so the changes in treatment and recommendations were done based on patient's characteristics. Visit 3 is oriented to identify barriers that impede the achievement of metabolic goals. The fourth visit reinforced the knowledge acquired in previous visits and established a program to follow for the next year. In annual evaluations (visits 5, 6 and 7), the barriers and their proposed solutions were reviewed. Every visit evaluates the abilities acquired previously and a structured examination was applied asking every patient to undertake activities related to self-care (daily foot check, glucose monitoring, toothbrushing, etc). In each visit and intervention, the strategies applied were directed to empower patients focusing on their needs, beliefs and resources. Blood samples are taken to evaluate HbAlc, lipid profile, and creatinine (Bio-Rad Variant II Turbo HbA1c Kit 2, with high-performance liquid chromatography method). Albumin/creatinine ratio (SYNCHRON CX system with colorimetric method) was used for screening diabetic nephropathy at baseline and annual visits. An ECG is also done in the first and annual evaluations. Body composition was assessed by bioimpedance (JAWON medical ioi353). Between annual visits, the patients were regularly checked by their personal physician. For this analysis, the diagnosis of anxiety and depression was established according to the validated questionnaire for anxiety and depression symptoms (Hospital Anxiety and Depression Scale). ${ }^{18} 19$ Online supplemental appendix 2 and figure 1 shows a flow diagram of the structure of the program and sessions. In the CAIPaDi, a total of 2741 patients have been evaluated in the first visit. So far 2275 patients have reached the second visit, 1989 in the third visit, 1787 are in the fourth visit, 914 have reached visit 5 (first annual evaluation), 503 in visit 6 (second annual evaluation), and 238 patients have reached visit 7 (3 years of follow-up).

\section{IQVIA CDM input parameters}

Anonymized clinical records of the CAIPaDi patients were provided by the hospital. A detailed summary of the variables is shown in the online supplemental appendix 3 . To avoid any overestimation of effectiveness from the intervention, we only considered data from the cohort of patients with the latest follow-up available (3 years, $\mathrm{n}=238$ ).

The baseline characteristics of the patients for both arms in the analysis were assumed to be the same and were obtained from the CAIPaDi baseline patient characteristics (table 1).

For the effectiveness of the intervention arm (the CAIPaDi program), the model was populated using the anonymized patient record dataset; whereas for the reference group (standard model of healthcare), we selected a set of public reports that show the current landscape of the clinical condition of the patients with T2DM covered by the Mexican public healthcare institutions: the Mexican National Nutrition Survey 2018, ${ }^{12}$ the demographic indicators from the National Institute of Statistics and Geography (INEGI) ${ }^{4}$ and the pharmacological treatment effectiveness reported ${ }^{20}{ }^{21}$ (more information regarding the effectiveness of the treatments is presented in online supplemental appendix 4).

As the analysis was developed from a payer's perspective, only direct costs were taken into account: direct medical costs associated with the programs (CAIPaDi and standard healthcare model), diagnostics and imaging, and costs of complications (cardiovascular disease, kidney disease, ulcer, amputation, neuropathy and eye disease).

The cost of the CAIPaDi program in the first year was estimated at $\$ 2706$, and for second and subsequent years at $\$ 582$, and included the healthcare resources per visit. Whereas for the usual treatment, the cost per year was estimated in $\$ 210$, and included only, in a conservative scenario, the pharmacological treatment recommended by the Mexican guidelines: metformin $1700 \mathrm{mg}$ daily, glybenclamide $10 \mathrm{mg}$ daily and Neutral Protamine Hagedorn insulin $0.4 \mathrm{UI} / \mathrm{kg}$. Cost composition is detailed in the online supplemental appendix 5 . 
Table 1 Summary of clinical and demographic baseline characteristics

\begin{tabular}{|c|c|c|}
\hline & Mean & SD \\
\hline \multicolumn{3}{|l|}{ Patient demographics } \\
\hline Age (years) & 57.61 & 8.89 \\
\hline Duration of T2DM (years) & 1.32 & 1.57 \\
\hline Percentage male & 45 & - \\
\hline \multicolumn{3}{|l|}{ Baseline risk factors } \\
\hline $\mathrm{HbA1c}(\%)$ & 7.65 & 2.18 \\
\hline Systolic blood pressure $(\mathrm{mm} \mathrm{Hg})$ & 128.72 & 16.36 \\
\hline Total cholesterol (mg/dL) & 194.73 & 44.55 \\
\hline $\mathrm{HDL}-\mathrm{c}(\mathrm{mg} / \mathrm{dL})$ & 42.88 & 10.61 \\
\hline LDL-c (mg/dL) & 114.06 & 42.64 \\
\hline Triglyceride (mg/dL) & 206.05 & 144.99 \\
\hline Body mass index $\left(\mathrm{kg} / \mathrm{m}^{2}\right)$ & 29.17 & 4.40 \\
\hline
\end{tabular}

$\mathrm{N}=238$ patients who completed the 3-year evaluation.

$\mathrm{HbA1c}$, glycated hemoglobin; HDL-c, high-density lipoprotein cholesterol; LDL-c, low-density lipoprotein cholesterol; T2DM, type 2 diabetes mellitus.

To present the most representative and updated costs of healthcare in Mexican institutions, only official sources were considered. The predominant sources of costs were: the Mexican Institute for Social Security (IMSS) diagnosis-related group data which include information about service costs and clinical pathways ${ }^{22}$; IMSS inpatient and outpatient unit $\operatorname{costs}^{23}$; direct costs due to acute adverse events estimated from a study of economic burden of T2DM in Mexico in $2013^{5}$; and finally, the unit cost of medications taken from the consolidated medicine purchasing data collected and published by IMSS in $2019 .^{24}$ All costs were updated to present value (2019) using the inflation rate calculator provided by the INEGI, if needed. ${ }^{25}$

Health outcomes were estimated as: LYs gained and QALYs using the IQVIA CDM to perform the costeffectiveness analysis over a 20-year horizon. According to the Mexican institutional normative, a discounted rate of $5 \%$ was applied in this study. ${ }^{26}$

\section{RESULTS}

The CAIPaDi intervention was associated with an improvement of most of the key clinical outcomes from basal visit (visit 1) to a 3-year follow-up evaluation (visit 7) (table 2). Based on the clinical outcomes, the IQVIA CDM estimates a reduction in the incidence of eye, renal and cardiovascular diseases (including all the specific categories for each one of these), as well as the incidence of diabetic foot and depression. Moreover, a longer time alive and free of complications was estimated for the CAIPaDi participants (online supplemental appendices 6 and 7$)$.

\section{Costs}

Table 3 provides a summary of the estimated differences between CAIPaDi and usual treatment in terms of use of resources. All costs are reported in US\$, using the average

Table 2 Effect of CAIPaDi from visit 1 to visit 7 in diabetes control variables, October 2013 - August 2018

\begin{tabular}{|c|c|c|c|c|c|}
\hline \multirow[b]{2}{*}{ Variable } & \multirow[b]{2}{*}{ Parameter } & \multirow[b]{2}{*}{ Goal (\%) } & \multirow{2}{*}{$\begin{array}{l}\text { Basal (visit 1) } \\
\text { Patients } \mathrm{n}=238(\%)\end{array}$} & \multirow{2}{*}{$\begin{array}{l}\text { 3-year follow-up (visit 7) } \\
\text { Patients } \mathrm{n}=238(\%)\end{array}$} & \multirow{2}{*}{$\begin{array}{l}\text { Change in percentage } \\
\text { points }\end{array}$} \\
\hline & & & & & \\
\hline \multirow{3}{*}{$\begin{array}{l}\text { Glycated hemoglobin } \\
\text { (\%) }\end{array}$} & $>9.0$ & $\leq 15$ & $50(21)$ & $21(9)$ & -12 \\
\hline & $7.0 \%-9.0$ & $>60$ & $62(26)$ & $62(26)$ & 0 \\
\hline & $<7.0$ & $>40$ & $126(53)$ & $155(65)$ & 12 \\
\hline \multirow{2}{*}{$\begin{array}{l}\text { Blood pressure } \\
(\mathrm{mm} \mathrm{Hg})\end{array}$} & $\geq 140 / 90$ & $\leq 35$ & $12(4)$ & $6(3)$ & -2 \\
\hline & $<130 / 80$ & $>25$ & $102(43)$ & $179(7)$ & 32 \\
\hline LDL-c (mg/dL) & $\geq 130$ & $\leq 37$ & $76(34)$ & $40(17)$ & -15 \\
\hline $\mathrm{HDL}-\mathrm{c}(\mathrm{mg} / \mathrm{dL})$ & $<100$ & & $238(100)$ & $238(100)$ & 0 \\
\hline Triglyceride (mg/dL) & $\leq 150$ & - & $97(41)$ & $138(58)$ & 17 \\
\hline $\begin{array}{l}\text { Albumin/creatinine } \\
\text { ratio }(\mathrm{mg} / \mathrm{g})\end{array}$ & $<30$ & - & $204(86)$ & $195(82)$ & -4 \\
\hline BMI $\left(\mathrm{kg} / \mathrm{m}^{2}\right)-$ normal & $<25$ & - & $38(16)$ & $47(20)$ & 4 \\
\hline Overweight & $(25-29.9)$ & - & $112(47)$ & $103(43)$ & -4 \\
\hline Obesity level I & $(30-34.9)$ & - & $68(29)$ & $70(29)$ & 1 \\
\hline Obesity level II & $(35-39.9)$ & - & $14(6)$ & $18(8)$ & 2 \\
\hline Obesity level III & $\geq 40$ & - & $6(3)$ & $0(0)$ & -3 \\
\hline
\end{tabular}

Percentages may not add up to $100 \%$ due to rounding. The goal refers to the expected percentage of patients in the value defined in the parameter column.

All the clinical outcomes are not reported but they are available from the authors on request. There were no hospitalizations for severe hypoglycemia.

BMI, body mass index; HDL-c, high-density lipoprotein cholesterol; LDL-c, low-density lipoprotein cholesterol. 
Table 3 Comparison of direct medical costs between CAIPaDi and usual treatment over 20 years (2019 US\$ prices)

\begin{tabular}{|lcc|}
\hline Variable & $\begin{array}{l}\text { Usual } \\
\text { treatment } \\
\text { (US\$) }\end{array}$ & $\begin{array}{l}\text { CAIPaDi } \\
\text { (US\$) }\end{array}$ \\
\hline Treatment & $38^{\star}$ & $4734 \dagger$ \\
\hline Diagnostics and imaging & 87 & 1975 \\
\hline Complications & & \\
\hline Cardiovascular disease & 5498 & 3832 \\
\hline Kidney disease & 3701 & 1917 \\
\hline Ulcer/amputation/neuropathy & 8154 & 4656 \\
\hline Eye disease & 1341 & 1024 \\
\hline Total costs & 18819 & 18138 \\
\hline $\begin{array}{l}\text { Differential mean cost over 20 } \\
\text { years, US\$ (95\% Cl) }\end{array}$ & -681 (-995 to -366$)$ \\
\hline
\end{tabular}

Access to the estimation technical documentation is available from the authors on request.

US $\$-$ Mexican peso exchange rate $=19.25739$. Average of exchange rate from December 2018 to December 2019.

Source: Central Bank of Mexico. ${ }^{6}$ Consulted: March 9, 2020.

*Includes only pharmacological treatment.

†Includes specialist visits, GP visits, facilitated meetings and use of at-distance support equipment.

GP, general practitioner.

exchange rate from December 2018 to December 2019 reported by the Central Bank of Mexico. ${ }^{6}$ Overall, the discounted cost of the usual treatment of T2DM per patient in the public sector is approximately US $\$ 18818$ and US\$18138 in CAIPaDi. However, the saving of complication-related treatments and management (\$7264) offset that additional cost. Moreover, the results show that the CAIPaDi saves an average of -US\$681 (95\% CI: $-\$ 995$ to $-\$ 366$ ) more than usual treatment, due to the decrease in diabetes complications.

\section{Health and economic outcomes}

Improvements in mean LYs gained and QALYs were projected over a 20-year time horizon (table 4). CAIPaDi patients were projected to gain on average 10.96 years (95\% CI: 10.84 to 11.1 ) compared with 10.46 years (95\% CI: 10.30 to 10.62) for patients receiving usual treatment. The mean QALYs were 6.84 (95\% CI: 6.71 to 6.96 ) vs 6.06 (95\% CI: 5.92 to 6.19 ) for usual treatment. This means that the CAIPaDi intervention produced a gain in mean LYs of 0.50 (95\% CI 0.46 to 0.54 ) and QALYs of $0.78(95 \%$ CI 0.75 to 0.80$)$.

CAIPaDi has a higher efficacy and lower associated costs. The benefit of the program is assessed in terms of the generated incremental cost-effectiveness ratio (ICER). Mean differences in cost and LYs gained as well as QALYs showed a dominance of CAIPaDi versus usual treatment.

\section{Sensitivity analyses}

We conducted a probabilistic sensitivity analysis that allowed us to quantify the level of confidence in the output of the model in relation to the uncertainty in the inputs required by the IQVIA CDM. The model was estimated 1000 times to generate outputs of both discounted costs and health outcomes. Figure 1 shows the scatter plot of the incremental cost against both LYs gained and QALYs for the intervention and for the usual treatment. In both scatter plots, around $60 \%$ are located exclusively within the lower-right quadrant of the cost-effectiveness plane, indicating that CAIPaDi is projected to be a dominant intervention, associated with an increased efficacy and savings in costs.

In order to evaluate the specific contribution of each CAIPaDi component in the glycemic control, a scenario sensitivity analysis was performed. The scenario without nutrition intervention resulted in a total of $10.9 \mathrm{LYs}$ and 6.75 QALYs, representing a decrease of $-0.06 \mathrm{LYs}$ and -0.08 QALYs from the base case, while the scenario

Table 4 Summary of health and economic outcomes over 20 years

\begin{tabular}{|c|c|c|}
\hline Variable & Usual treatment $(95 \% \mathrm{Cl})$ & CAIPaDi $(95 \% \mathrm{Cl})$ \\
\hline \multicolumn{3}{|l|}{ Health outcomes } \\
\hline Life expectancy (life-years gained) & 10.47 (10.30 to 10.62$)$ & 10.96 (10.84 to 11.1$)$ \\
\hline Differential life-years gained & 0.50 (0.46 to 0.54$)$ & \\
\hline QALYS & 6.06 (5.92 to 6.19$)$ & 6.84 (6.71 to 6.96$)$ \\
\hline Differential QALYs & $0.78(0.75$ to 0.80$)$ & \\
\hline \multicolumn{3}{|l|}{ Cost } \\
\hline 20-year direct medical cost & $\$ 18819(\$ 16731$ to $\$ 19545)$ & $\$ 18138$ (\$17 349 to $\$ 20045)$ \\
\hline Differential direct medical cost & $-\$ 681(-\$ 995$ to $-\$ 366)$ & \\
\hline \multicolumn{3}{|l|}{ Cost-effectiveness } \\
\hline ICER based on life expectancy $(95 \% \mathrm{Cl})$ & \multicolumn{2}{|c|}{$-\$ 13565$ per life year gained $(-\$ 1843$ to $-\$ 789)$} \\
\hline ICER based on QALYs (95\% Cl) & \multicolumn{2}{|c|}{$-\$ 874$ per QALY gained $(-\$ 1238$ to $-\$ 486)$} \\
\hline
\end{tabular}

ICER, incremental cost-effectiveness ratio; QALYs, quality-adjusted life years. 
without psychiatric intervention resulted in a total of 10.88 LYs gained and 6.72 QALYs for the CAIPaDi; this represents a decrease of -0.088 LYs and -0.12 QALYs, which lead to an increase of the ICER of the CAIPaDi without psychiatric intervention versus the usual treatment to US $\$ 3250$ per LY gained and US $\$ 2009$ per QALY. Even with this increase in the ICER, the CAIPaDi is still a cost-effective alternative. These results set a guideline for future analysis within the CAIPaDi program.

\section{DISCUSSION}

Patient training for self-management and the multidisciplinary healthcare attention are acknowledged as two significant complements to diabetes medical treatment. Nevertheless, to implement an attention model that includes these two components may be difficult due to budget limitations. The CAIPaDi program was designed to offer, at the same place, in the same visit and in a coordinated way, a comprehensive attention provided by specialists. It avoids multiple visits and assures the implementation of preventive and therapeutic actions. As a result, it reduces cost and increases the effectiveness of the management protocol, resulting in a dominant alternative compared with the usual treatment.

This report shows that a comprehensive program like CAIPaDi is an efficient investment in health. The results of the analysis, using the $\mathrm{CDM}$, demonstrate that CAIPaDi provides better clinical results in all measured variables. The HbA1c, blood pressure, low-density lipoprotein cholesterol, triglycerides, and weight reductions contribute to improve the patients' conditions in the middle term. In a cascade effect, the risks of cardiovascular, renal, and ophthalmologic diseases and diabetic foot, as well as depression, will be reduced; and this reduction in the risk of complications reduces the costs associated with them as well, resulting in lower total costs than the usual treatment. In the long term, the health consequences are not only a longer life expectancy than the usual treatment for T2DM, but a higher quality life expectancy, free of diabetes complications for the patient and savings due to avoiding complication events for the healthcare system, even if the costs associated with the intervention are higher than the usual treatment.

The model's base case results were confirmed by the probabilistic sensitivity analysis. This analysis was consistent with both health results, LYs gained and QALYs, and also with the associated costs. Thus, more than half of the potential results were placed as better health results and with lower costs. That is, the model estimates that CAIPaDi is a dominant alternative. In consequence, a health intervention like this seems to be an efficient investment for public healthcare institutions, and particularly it seems to be recommendable to expand the nutrition and psychiatric professionals' participation. The difference in treatment and management costs reflects the need for more healthcare professionals, facilitator's interventions and use of at-distance support equipment included in the CAIPaDi.
Evidence suggests that programs run by peers are efficient assisting in managing metabolic parameters of patients with diabetes. A meta-analysis developed by Teljeur et $a l^{27}$ suggests that self-management support education programs may be cost-effective. Moreover, Gilmer et $a t^{28}$ recently found that two technology-enhanced diabetes programs were cost-effective under a time horizon of 15-20 years in Mexico. Comparison of our results against other international programs is limited by the differential effect of local costs and access to care.

It is important to point out the model applied here has some limitations that need to be considered when assessing its relative generalizability. First, as all long-term models, it relies on projected clinical outcomes, in this case after a 3-year follow-up. The IQVIA CDM comprises simulations using predictive equations, and for the long-term follow-up this may have underestimated or overestimated some of the health gains associated with patients' self-management skills acquired from the CAIPaDi program. Differences in utility over 20 years would influence life expectancy and QALYs that we are not able to predict. However, the IQVIA CDM is a widely published and validated model that has been used to estimate long-term clinical outcomes in T2DM within many contexts and comparing different healthcare technologies. ${ }^{29}$

On the other hand, it is important to consider that the perspective of this analysis was from a public health service and only considers direct medical costs for both interventions. Hence, this analysis does not include discounted indirect costs or additional benefits, and this may have had an effect of subestimation of the total costs and, therefore, a bias on the estimated ICER, which could be even better.

Given the beneficial results in the indicators of metabolic control, quality of care, in cost-benefit, and years of quality of life gained, it will be presented to stakeholders and policymakers in health to evaluate the extrapolation and implementation in a greater number of centers. It is also important to show this evidence so that the model can be applied in other chronic diseases.

In summary, the CAIPaDi program is a cost-effective intervention that provides additional benefits and longterm saving over the usual care provided in the Mexican public health institutions.

\section{Author affiliations}

${ }^{1}$ CAIPaDi, National Institute of Medical Sciences and Nutrition Salvador Zubiran Tlalpan, Mexico

${ }^{2}$ IQVIA, Fairfax, Virginia, USA

${ }^{3}$ Real-World Insights, IQVIA, Mexico City, Mexico

${ }^{4}$ Blutitude Health Care Intelligence, Mexico City, Mexico

${ }^{5}$ Department of Cornea and Refractive Surgery, Institute of Ophthalmology Conde de Valenciana Foundation IAP, Mexico City, Mexico

${ }^{6}$ Endocrinology and Metabolism, National Institute of Medical Sciences and Nutrition Salvador Zubiran, Tlalpan, Mexico

${ }^{7}$ Escuela de Medicina y Ciencias de la Salud, Tecnologico de Monterrey, Monterrey, Mexico

${ }^{8}$ National Institute of Medical Sciences and Nutrition Salvador Zubiran, Tlalpan, Mexico 
Collaborators María Teresa Alcántara-Garcés, Denise Arcila-Martínez, Rodrigo Arizmendi-Rodríguez, Michelle Díaz-Pineda, Humberto Del Valle-Ramírez, Arturo Flores García, Fernanda Garnica-Carrillo, Eduardo González-Flores, Mariana Granados-Arcos, Héctor Infanzón-Talango, María Victoria Landa-Anell, Claudia Lechuga-Fonseca, Marco Antonio Melgarejo-Hernández, Liliana Pérez-Peralta, Sofía Ríos-Villavicencio, David Rivera de la Parra, Francis Rojas-Torres, Sandra SainosMuñoz, Alejandra Sierra-Esquivel, María Luisa Velasco-Pérez, Héctor VelázquezJurado, Andrea Villegas-Narvaez, Luz Elena Urbina-Arronte, Verónica Zurita-Cortés.

Contributors Research idea and study design were from DK-S, FJG-P, CAA-S, SH$\mathrm{J}$ and ACG-U. SH-J, ACG-U and PA wrote the manuscript. RG-P and LAS-T made the statistical analysis. The remaining authors revised the manuscript critically for important intellectual content. The group of study CAIPaDi is composed of all the healthcare professionals attending the patients.

Funding Unrestricted grant from Eli-Lilly, Mexico.

Competing interests CAA-S is an editorial board member for the BMJ Open Diabetes Research \& Care Journal. There are no other potential conflicts of interest relevant to this article.

Patient consent for publication Not required

Provenance and peer review Not commissioned; externally peer reviewed.

Data availability statement All data relevant to the study are included in the article or uploaded as supplemental information.

Supplemental material This content has been supplied by the author(s). It has not been vetted by BMJ Publishing Group Limited (BMJ) and may not have been peer-reviewed. Any opinions or recommendations discussed are solely those of the author(s) and are not endorsed by BMJ. BMJ disclaims all liability and responsibility arising from any reliance placed on the content. Where the content includes any translated material, BMJ does not warrant the accuracy and reliability of the translations (including but not limited to local regulations, clinical guidelines, terminology, drug names and drug dosages), and is not responsible for any error and/or omissions arising from translation and adaptation or otherwise.

Open access This is an open access article distributed in accordance with the Creative Commons Attribution Non Commercial (CC BY-NC 4.0) license, which permits others to distribute, remix, adapt, build upon this work non-commercially, and license their derivative works on different terms, provided the original work is properly cited, appropriate credit is given, any changes made indicated, and the use is non-commercial. See: http://creativecommons.org/licenses/by-nc/4.0/.

ORCID iDs

Sergio Hernández-Jiménez http://orcid.org/0000-0003-3080-8708

Ana Cristina García-Ulloa http://orcid.org/0000-0003-0653-4938

Luis Arturo Sánchez-Trujillo http://orcid.org/0000-0003-1543-3776

Carlos Alberto Aguilar-Salinas http://orcid.org/0000-0001-8517-0241

\section{REFERENCES}

1 Cisneros-González N, Ascencio-Montiel I de J, Libreros-Bango VN, et al. Índice de amputaciones de extremidades inferiores en pacientes Con diabetes. Rev Med Inst Mex Seguro Soc 2016;54:472-9.

2 Méndez-Durán A, Ignorosa-Luna MH, Pérez-Aguilar G. Estado actual de las terapias sustitutivas de la función renal en El Instituto Mexicano del Seguro social. Rev Med Inst Mex Seguro Soc 2016;54:588-93.

3 Herrington WG, Alegre-Díaz J, Wade R, et al. Effect of diabetes duration and glycaemic control on 14-year cause-specific mortality in Mexican adults: a blood-based prospective cohort study. Lancet Diabetes Endocrinol 2018;6:455-63.

4 Instituto Nacional de Estadística y Geografía (INEGI). Defunciones POR diabetes mellitus POR entidad federativa de residencia habitual de la persona fallecida $Y$ Grupo quinquenal de edad según sexo, 2016. Available: https://www.inegi.org.mx/app/tabulados/ interactivos/?pxq=Mortalidad_Mortalidad_04_c9a3e93b-1fa3-4ff78856-dcd9b078afbf

5 Barraza-Lloréns M, Guajardo-Barrón V, Picó J. Carga económica de la diabetes mellitus en México, 2013. México: DF Funsalud, 2015.

6 Bank of Mexico. Exchange rate to SETTLE obligations denominated in US dollars, payable in the Mexican Republic. Average daily reported estimated for Mexico for 2013, 2013. Available: https:// www.banxico.org. $\mathrm{mx} /$ tipcamb/main.do?page=tip\&idioma=sp\#

7 Almeda Valdés P, García García E, Aguilar Salinas CA. Implementación del tratamiento multidisciplinario; Manejo integral del paciente Con diabetes mellitus. en: Acciones para enfrentar a la diabetes. Documento de postura. academia Nacional de medicina, edit Intersistemas, CONACYT. Primera edición. Intersistemas, Mexico City, 20115: 194-8.

8 Brocco E, Ninkovic S, Marin M, et al. Diabetic foot management: multidisciplinary approach for advanced lesion rescue. J Cardiovasc Surg 2018;59:670-84.

9 Simmons D, Wenzel HZJ. A Primary Health-Care System Approach to Improving Quality of Care and Outcomes in People with Diabetes: The University of Pittsburgh Medical Center Experience. In: Simmons D, Wenzel H, Zgibor JC, eds. Integrated diabetes care. Cham: Springer International Publishing, 2017: 51-64. http://link. springer.com/

10 McGill M, Felton A-M, Global Partnership for Effective Diabetes Management. New global recommendations: a multidisciplinary approach to improving outcomes in diabetes. Prim Care Diabetes 2007;1:49-55.

11 Hernández-Jiménez S, García-Ulloa AC, Bello-Chavolla OY, et al. Long-Term effectiveness of a type 2 diabetes comprehensive care program. The CAIPaDi model. Diabetes Res Clin Pract 2019;151:128-137.

12 Shamah-Levy T, Vielma-Orozco E, Heredia-Hernández O. Encuesta Nacional de Salud Y Nutrición 2018-19: Resultados Nacionales. Cuernavaca, México: Instituto Nacional de Salud Pública, 2020. https://ensanut.insp.mx/encuestas/ensanut2018/informes.php

13 Sosa-Rubí SG, Contreras-Loya D, Pedraza-Arizmendi D, et al. Cost-effectiveness analysis of a multidisciplinary health-care mode for patients with type-2 diabetes implemented in the public sector in Mexico: a quasi-experimental, retrospective evaluation. Diabetes Res Clin Pract 2020;167:108336.

14 González L, Elgart JF, Gagliardino JJ. [Education of people with type 2 diabetes through peers with diabetes: is it cost effective?]. Medwave 2015;15:e6348.

15 Hernández-Jiménez S, Garcia-Ulloa C, Mehta R, et al. Innovative models for the empowerment of patients with type 2 diabetes: the CAIPaDi program. Recent Pat Endocr Metab Immune Drug Discov 2014;8:202-9.

16 Palmer AJ, Roze S, Valentine WJ, et al. The core diabetes model: projecting long-term clinical outcomes, costs and cost-effectiveness of interventions in diabetes mellitus (types 1 and 2) to support clinical and reimbursement decision-making. Curr Med Res Opin 2004;20 Suppl 1:S5-26.

17 McEwan P, Foos V, Palmer JL, et al. Validation of the IMS core diabetes model. Value Health 2014;17:714-24.

18 Zigmond AS, Snaith RP. The hospital anxiety and depression scale. Acta Psychiatr Scand 1983;67:361-70.

19 López-Alvarenga JC, Vázquez-Velázquez V, Arcila-Martínez D. Exactitud $Y$ utilidad diagnóstica del Hospital anxiety and depression scale (had) en Una muestra de sujetos obesos mexicanos. Rev Invest Clin 2002:54:403-9.

20 White JL, Buchanan P, Li J, et al. A randomized controlled trial of the efficacy and safety of twice-daily saxagliptin plus metformin combination therapy in patients with type 2 diabetes and inadequate glycemic control on metformin monotherapy. BMC Endocr Disord 2014;14:17

21 Douek IF, Allen SE, Ewings P, et al. Continuing metformin when starting insulin in patients with type 2 diabetes: a double-blind randomized placebo-controlled trial. Diabet Med 2005;22:634-40.

22 Arroyave MG, Aburto R. Grupos Relacionados Con El Diagnóstico: Producto Hospitalario. GRD-IMSS: 2014. México: Primera, Instituto Mexicano del Seguro Social, 2016.

23 Diario Oficial de la Federación (DOF). Agreement ACDO. AS3 HCT.270219/90.P.DF, concerning to the unit costs per level of health care updated to 2019. Official Journal of the Federation 2019.

24 Instituto Mexicano del Seguro Social (IMSS). Portal de compras del IMSS, 2019. Available: http://compras.imss.gob.mx/

25 Instituto Nacional de Estadística y Geografía (INEGI). Índice Nacional de Precios al Consumidor. Índice General, 2019. Available: https:// www.inegi.org.mx/app/indicesdeprecios/calculadorainflacion.aspx

26 Consejo de Salubridad General (CSG). Guía para La conducción de estudios de evaluación económica para La actualización del Cuadro Básico Y Catálogo de Insumos del sector Salud. Edición 2017, 2017. Available: http://www.csg.gob.mx/contenidos/priorizacion/ cuadro-basico/guias/guias.html

27 Teljeur C, Moran PS, Walshe S, et al. Economic evaluation of chronic disease self-management for people with diabetes: a systematic review. Diabet Med 2017;34:1040-9.

28 Gilmer T, Burgos JL, Anzaldo-Campos MC, et al. Cost-Effectiveness of a Technology-Enhanced diabetes care management program in Mexico. Value Health Reg Issues 2019;20:41-6.

29 Dadwani RS, Laiteerapong N. Economic simulation modeling in type 2 diabetes. Curr Diab Rep 2020;20:24. 